Article

\title{
Effect of Deformation Temperature on Mechanical Properties and Deformation Mechanisms of Cold-Rolled Low C High Mn TRIP/TWIP Steel
}

\author{
Zhengyou Tang ${ }^{1, *}$, Jianeng Huang ${ }^{1, *}$, Hua Ding ${ }^{1}$, Zhihui Cai ${ }^{1}$, Dongmei Zhang ${ }^{2}$ \\ and Devesh Misra ${ }^{3}$ \\ 1 School of Materials Science and Engineering, Northeastern University, Shenyang 110819, China; \\ neuhd@sina.com (H.D.); neuczh@sina.com (Z.C.) \\ 2 Shenyang Liming Aero-Engine Corporation, AECC, Shenyang 110043, China; 15040279961@163.com \\ 3 Laboratory for Excellence in Advanced Steel Research, Department of Metallurgical, Materials and \\ Biomedical Engineering, University of Texas at El Paso, El Paso, TX 79968, USA; dmisra2@utep.edu \\ * Correspondence: tangzy@smm.neu.edu.cn (Z.T.); Huangjnd@163.com (J.H.)
}

Received: 22 May 2018; Accepted: 20 June 2018; Published: 22 June 2018

\begin{abstract}
The microstructure and mechanical properties of cold-rolled Fe-18Mn-3Al-3Si-0.03C transformation induced plasticity/twinning induced plasticity (TRIP/TWIP) steel in the temperature range of 25 to $600{ }^{\circ} \mathrm{C}$ were studied. The experimental steel exhibited a good combination of ultimate tensile strength (UTS) of $905 \mathrm{MPa}$ and total elongation (TEL) of $55 \%$ at room temperature. With the increase of deformation temperature from 25 to $600{ }^{\circ} \mathrm{C}$, the stacking fault energy (SFE) of the experimental steel increased from 14.5 to $98.8 \mathrm{mJm}^{-2}$. The deformation mechanism of the experimental steel is controlled by both the strain induced martensite formation and strain induced deformation twinning at $25{ }^{\circ} \mathrm{C}$. With the increase of deformation temperature from 25 to $600{ }^{\circ} \mathrm{C}$, TRIP and TWIP effect were inhibited, and dislocation glide gradually became the main deformation mechanism. The UTS decreased monotonously from 905 to $325 \mathrm{MPa}$ and the TEL decreased (from 55 to $36 \%, 25-400{ }^{\circ} \mathrm{C}$ ) and then increased (from 36 to $64 \%, 400-600{ }^{\circ} \mathrm{C}$ ). The change in mechanical properties is related to the thermal softening effect, TRIP effect, TWIP effect, DSA, and dislocation slip.
\end{abstract}

Keywords: deformation temperature; deformation mechanisms; tensile properties; TRIP/TWIP steel

\section{Introduction}

Low C, high Mn transformation-induced plasticity/twinning-induced plasticity (TRIP/TWIP) steels are considered to be one of the most attractive materials for automotive steels because of their excellent combination of strength $(>900 \mathrm{MPa})$ and ductility $(>50 \%)$ at room temperature [1-5]. The outstanding mechanical properties of TRIP/TWIP steels at room temperature are due to the remarkable work-hardening behavior resulting from the evolution of multiple microstructural processes including dislocation slip, formation of stacking fault, deformation induced martensitic transformation and deformation twinning [3-7]. The $\alpha_{\mathrm{bcc}} / \varepsilon_{\mathrm{hcp}}$-martensite and mechanical twins (transformed from austenite during deformation) act as planar obstacles and reduce the mean free path of dislocation glide, promoting working hardening and delaying necking, which results in large uniform elongation $[5,7,8]$. Recently, it was proposed that the influence of dynamic strain aging (DSA) phenomenon on the mechanical behavior of high Mn TWIP steels should not be ignored, and DSA phenomena may occur in a particular temperature range [9-12]. The loss of ductility caused by DSA has been reported for ferritic steel, low carbon steel, and dual-phase steel at the DSA temperature range [13-16]. A change of temperature can influence DSA [17]. Thus, considering the complexity 
of deformation mechanisms of TRIP/TWIP steel, it is necessary to understand the deformation mechanisms of TRIP/TWIP steels at different temperatures.

The mechanical properties and deformation mechanisms of TRIP/TWIP steels exhibit a strong dependence on temperature and stacking fault energy (SFE) $[8,18]$. It is well established that the main governing factor responsible for the deformation mechanism in TRIP/TWIP steels is the SFE [19] and the SFE increased with the increased of temperature [7,20]. According to Curtze et al. [21], when SFE below $18 \mathrm{mJm}^{-2}$, strain induced martensite transformation is the favored transformation mechanism. When the SFE increases from $\sim 18$ to $45 \mathrm{mJm}^{-2}$, deformation-induced twinning occurs [21,22]. When SFE exceeds $45 \mathrm{mJm}^{-2}$, dislocation glide controls the work hardening [18,21]. The study of SFE for specific plasticity mechanisms is important because deformation mode can affect the mechanical properties of materials or result in deleterious effects. For example, DSA in some TRIP/TWIP steels $[8,11,17,23]$.

A few studies were devoted to TRIP/TWIP steels deformed at different temperatures [7,18,22,24]. Linderov et al. [7] investigated the deformation mechanisms of austenitic TRIP/TWIP steels at two different temperatures-ambient and $373 \mathrm{~K}\left(100{ }^{\circ} \mathrm{C}\right)$ - and observed that the temperature strongly affects the deformation-induced processes of metastable austenitic steels. However, a systematic study on the effect of deformation temperature on the deformation mechanism and mechanical properties of TRIP/TWIP steels was not carried out. Martin et al. [24] studied the deformation mechanism in a high-alloy austenitic CrMnNi austenitic TRIP/TWIP steel in the temperature range of -60 and $200{ }^{\circ} \mathrm{C}$, and demonstrated that the change in deformation mechanism was caused by both temperature and SFE. Asghari et al. [19] investigated a TRIP/TWIP steel (Fe-0.07C-18Mn-2Si-2Al) over a wide temperature range from 25 to $1000{ }^{\circ} \mathrm{C}$ through compression tests, and showed that the flow stress was strongly dependent on the deformation temperature. Eskandari et al. [25] also conducted compressive tests on a TRIP/TWIP steel (Fe-0.11C-21Mn-2.70Si-1.60Al-0.01Nb-0.01Ti-0.10Cr) from 25 to $1000{ }^{\circ} \mathrm{C}$ to investigate the mechanical behavior of the TRIP/TWIP steel. They concluded that both the strain-induced martensite formation and mechanical twinning controlled the plastic deformation in the temperature range of $25-150{ }^{\circ} \mathrm{C}$. In summary, a systematic study on the influence of deformation temperature (over a wide range of temperature) on the deformation mechanism and tensile properties of TRIP/TWIP steel is required at this time.

Thus, The present study is aimed at studying the effect of deformation temperature (over a temperature range of 25 to $600{ }^{\circ} \mathrm{C}$ ) on the deformation mechanism and tensile properties of TRIP/TWIP steel to get a comprehensive understanding of warm/hot deformation characteristics of TRIP/TWIP steel, having a better insight into the evolution of deformation mechanism in TRIP/TWIP steel at different temperatures, which can provide reference for the best design of some processing route such as warm stamping, hot rolling, thermo-mechanical process. The experimental results have a certain practical significance in the deformation technology of TRIP/TWIP steel in different temperature ranges.

\section{Materials and Methods}

The nominal chemical composition of the investigated TRIP/TWIP steel was Fe-18.10Mn-3.1Al-3.2Si-0.03C (in wt\%). A $50 \mathrm{~kg}$ ingot was cast after melting the steel in a vacuum furnace. The ingot was heated at $1200{ }^{\circ} \mathrm{C}$ for $2 \mathrm{~h}$ and hot forged to rods of section size $100 \mathrm{~mm} \times$ $30 \mathrm{~mm}$, followed by air cooling to room temperature. Subsequently, the rod was soaked at $1200{ }^{\circ} \mathrm{C}$ for $2 \mathrm{~h}$, then hot rolled to $3 \mathrm{~mm}$ thickness. The hot rolled plate was reheated to $1100{ }^{\circ} \mathrm{C}$ for $30 \mathrm{~min}$ and cold-rolled to sheet of $1 \mathrm{~mm}$ thickness. Finally, the cold rolled sheet was solution-treated at $1000^{\circ} \mathrm{C}$ for $10 \mathrm{~min}$ and water-quenched. Tensile specimens with a gage length of $25 \mathrm{~mm}$ and width of $6 \mathrm{~mm}$ were machined from the cold rolled sheet with the tensile axis parallel to the rolling direction. Tensile tests were conducted from 25 to $600{ }^{\circ} \mathrm{C}\left(25\right.$ (room temperature), 200, 300, 400, 500, and $600{ }^{\circ} \mathrm{C}$, referred to as 25-sample, 200-sample, 300-sample, 400-sample, 500-sample, and 600-sample, respectively) using CMT5105 tensile testing machine at a constant strain rate of $1.67 \times 10^{-3} \mathrm{~s}^{-1}$. In order to heat the 
specimen uniformly, high-temperature deformation testing was carried out in a sealed insulation furnace, and a heat-resistant alloy fixture was used. The sample was heated to the deformation temperature at the rate of $10^{\circ} \mathrm{C} / \mathrm{s}$ and maintained at the test temperature for $5 \mathrm{~min}$.

Microstructure was studied by optical microscope (OM, OLYMPUS-GSX500, OLYMPUS, Tokyo, Japan), field-emission scanning electron microscope (FE-SEM, Supra, SSX-550, Shimadzu, Tokyo, Japan) and a field-emission transmission electron microscope (FE-TEM, FEI, TECNAI G2-20, operated at $200 \mathrm{kV}$, FEI, Hillsboro, OR, USA). Samples were cut from the tensile specimens near the fracture surface after the tensile tests. Samples were mechanically polished and subsequently electropolished at room temperature in an electrolyte containing $95 \% \mathrm{CH}_{3} \mathrm{COOH}+5 \% \mathrm{HClO}_{4}$ solution to remove any strain-induced martensite that may have formed during mechanical polishing. Phase analysis was carried out by X-ray diffraction (XRD, Rigaku, D/Max2250/PC, Rigaku Corporation, Tokyo, Japan) with $\mathrm{CuK}_{\alpha}$ radiation. Before OM and SEM observations, the samples were etched with $4 \%$ nital. For TEM studies, thin foils were first mechanically ground to $\sim 40 \mu \mathrm{m}$ thickness, then twin-jet polished (Struers, Tenupol-5, Struers, Copenhagen, Denmark) in a solution of 5\% perchloric acid and $95 \%$ alcohol at $\sim 20^{\circ} \mathrm{C}$. Annealing and deformation twins, stacking faults, martensite, dislocation walls, and slip bands were identified using a TECNAI G2-20 TEM.

\section{Results}

\subsection{Mechanical Properties and Work Hardening Behavior}

Figure 1 shows engineering stress-strain curves of the experimental steel at different tensile test temperatures. The statistical results of ultimate tensile strength (UTS), total elongation (TEL), and the product of ultimate tensile strength and total elongation (PSE) of the experimental steel at different deformation temperatures are summarized in Table 1. Combining Figure 1 and Table 1, it may be noted that the deformation temperature has a significant influence on the mechanical behavior of the investigated steel. The thermal softening effect is obvious with the increase of temperature. The UTS and PSE continuously decreased with the increase of temperature from 25 to $600{ }^{\circ} \mathrm{C}$, a behavior similar to the results of Shterner et al. [3]. The TEL decreased from 55 to $36 \%$, as the temperature increased from 25 to $200{ }^{\circ} \mathrm{C}$. Interestingly, TEL remained almost unchanged at $36 \%$, when the deformation temperature was in the range of 200 to $400{ }^{\circ} \mathrm{C}$. Then, TEL increased from 36 to $64 \%$ with increase of tensile test temperature from 400 to $600{ }^{\circ} \mathrm{C}$.

It may be noted that the periodic serration and step-like fluctuation appeared in the engineering stress-strain curves, when the deformation temperature was in the range of 200 to $400{ }^{\circ} \mathrm{C}$ (Figure 1). According to the conclusion by Lee et al. [11] and Lan et al. [26], the periodic serration and step-like fluctuation are representative of DSA and Portevin Le-Chatelier (PLC) behavior. However, DSA did not appear when the tensile tests were carried out at other temperatures. This indicates that the experimental steel is most susceptible to experience DSA in the temperature range of $200-400{ }^{\circ} \mathrm{C}$.

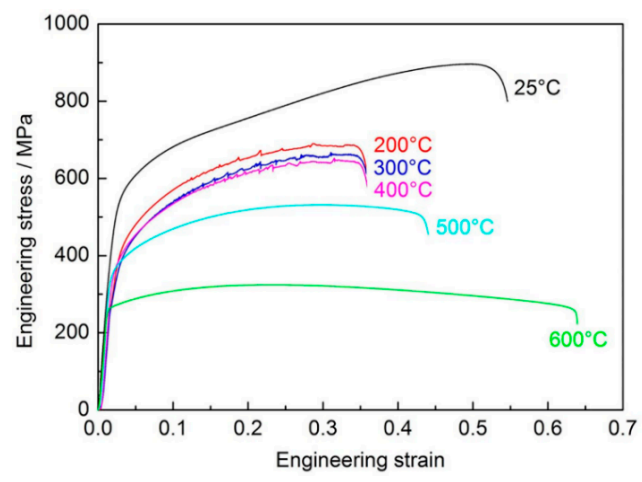

Figure 1. Engineering strain-stress curves at different tensile test temperatures of the experimental steel. 
Table 1. Mechanical properties of experimental steel at different tensile test temperatures.

\begin{tabular}{cccc}
\hline Temperature $\left({ }^{\circ} \mathbf{C}\right)$ & UTS (MPa) & TEL (\%) & PSE (GPa\%) \\
\hline 25 & $905( \pm 7)$ & $55( \pm 0.2)$ & $49.8( \pm 0.5)$ \\
200 & $690( \pm 10)$ & $36( \pm 0.3)$ & $24.8( \pm 0.6)$ \\
300 & $670( \pm 6)$ & $36( \pm 0.3)$ & $24.1( \pm 0.4)$ \\
400 & $650( \pm 8)$ & $36( \pm 0.2)$ & $23.4( \pm 0.4)$ \\
500 & $530( \pm 6)$ & $44( \pm 0.5)$ & $23.3( \pm 0.5)$ \\
600 & $325( \pm 3)$ & $64( \pm 0.6)$ & $20.8( \pm 0.4)$ \\
\hline
\end{tabular}

Figure 2 presents the instantaneous work hardening exponent (n) and true stress as a function of true strain, where the $\mathrm{n}$ value was calculated by $\mathrm{n}=\mathrm{d} \ln \sigma / \mathrm{d} \ln \varepsilon$ [27]. The instantaneous work hardening exponent $(\mathrm{n})$ can further reveal the deformation behavior of the experimental steel during straining. Based on Figure 2, it can be seen that the variation in $n$ value was different in samples deformed at different temperatures. The instantaneous work hardening exponent (n) curves can be divided into three stages. In summary, the $n$ value decreased sharply in $S_{1}$ (elastic stage) for all the samples. During $S_{2}$, a rapid increase in the $\mathrm{n}$ value of 25 -sample indicated a high strain hardening rate. A strong fluctuation in the $\mathrm{n}$ value was observed for 200-sample, 300-sample and 400-sample, and a gradual increase in the $\mathrm{n}$ value for 500 -sample and 600 -sample. Finally, the $\mathrm{n}$ value of 25 -sample, 200-sample, 300-sample, and 400-sample decreased rapidly in $S_{3}$, while, for 500-sample and 600-sample, the decrease was slow.
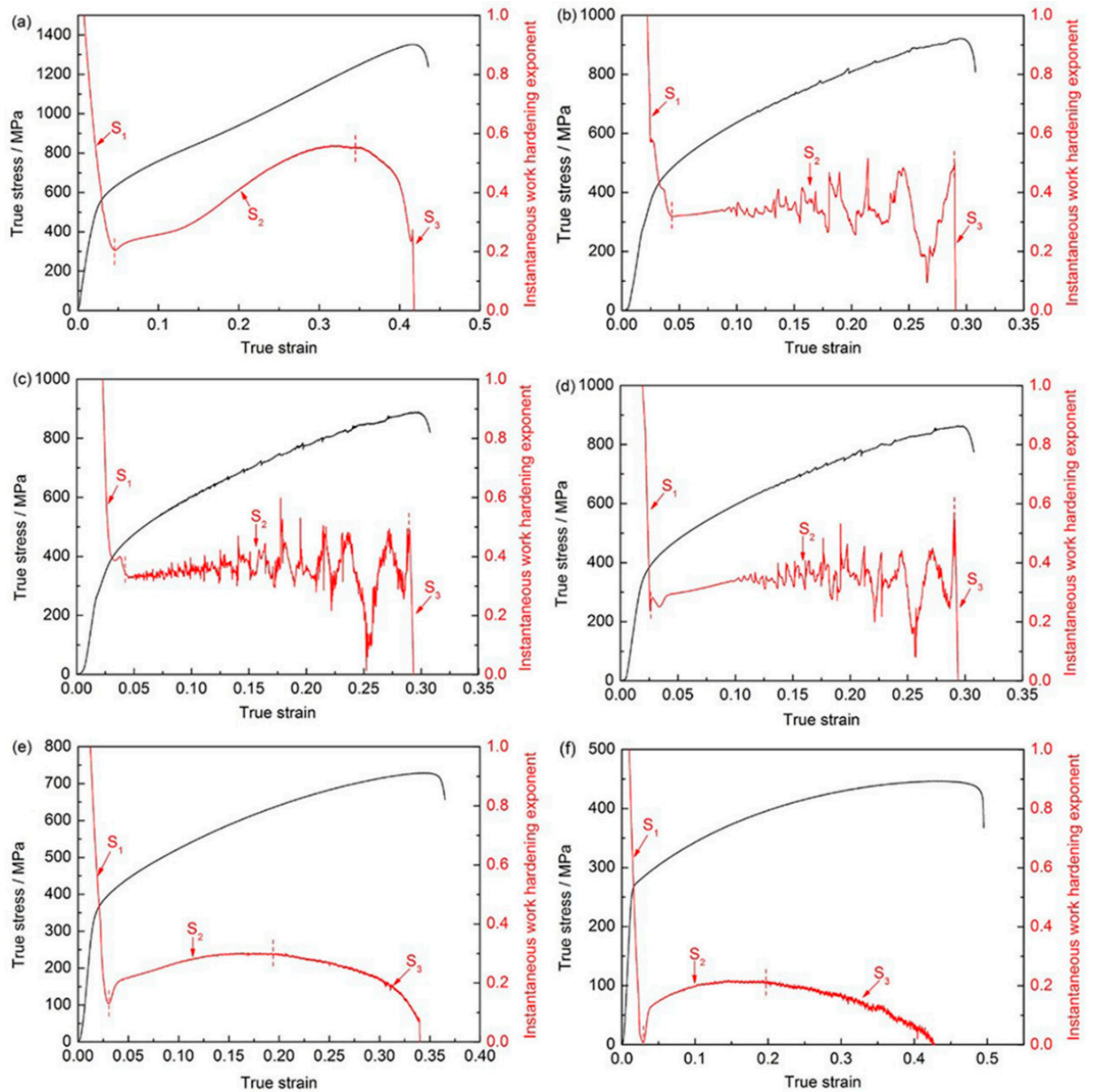

Figure 2. Instantaneous work hardening exponent (n) and true stress versus true strain of the experimental steel after deformation at different temperatures of (a) $25{ }^{\circ} \mathrm{C}$; (b) $200{ }^{\circ} \mathrm{C}$; (c) $300{ }^{\circ} \mathrm{C}$; (d) $400{ }^{\circ} \mathrm{C}$; (e) $500{ }^{\circ} \mathrm{C}$; and (f) $600{ }^{\circ} \mathrm{C}$. $\left(\mathrm{S}_{1} \sim \mathrm{S}_{3}\right.$ mean stage $\left.1-3\right)$. 


\subsection{Microstructure}

Figure 3 shows the X-ray diffraction patterns of the investigated samples before and after tensile deformation at different temperatures. With reference to the work of Egea et al. [28], the percentage of volume fraction of each phase for each temperature configuration has been calculated and summarized in Table 2. It can be seen from Figure 3 and Table 2 that the microstructure of experimental sample before the tensile test was mainly composed of $\gamma$-fcc phase (austenite, $66.4 \%$ ), $\alpha$-bcc phase (ferrite, $25.8 \%$ ) and some $\varepsilon$-hcp phase ( $\varepsilon$-martensite, $7.8 \%$ ). After deformation at $25^{\circ} \mathrm{C}$, the peaks of $111_{\gamma}$, $200_{\gamma}, 220_{\gamma}$, and $311_{\gamma}$ for $\gamma$-fcc phase became weak (the volume fraction of austenite decreased to $51.6 \%$ ), but the diffraction peaks of $110_{\alpha}, 200_{\alpha}$, and $211_{\alpha}$ for $\alpha$-bcc phase were enhanced (the volume fraction of $\alpha^{\prime}$-martensite increased to $15.8 \%$ ), which indicates that significant TRIP effect took place during tensile deformation at $25{ }^{\circ} \mathrm{C}$. With the increase of deformation temperature from 300 to $600{ }^{\circ} \mathrm{C}$, the peaks of $110_{\varepsilon}$ and $002_{\varepsilon}$ for $\varepsilon$-hcp phase disappeared, and the amount of austenite increased to $\sim 73.3 \%$ (see Table 2 ). This may be caused by the reversion from $\varepsilon$-martensite to austenite during tensile deformation.

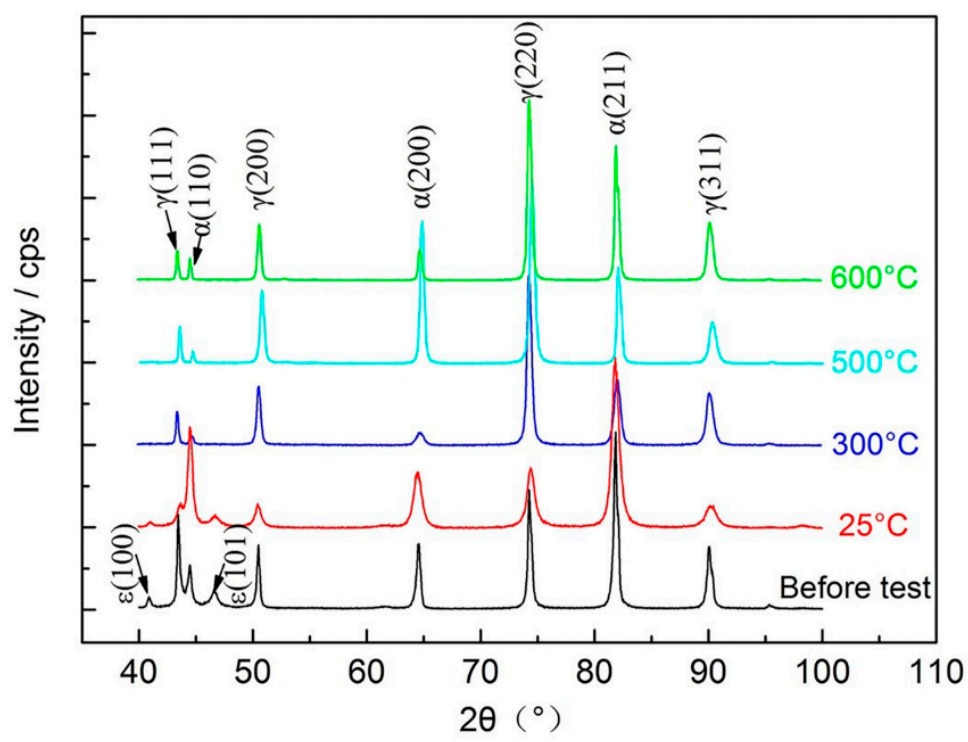

Figure 3. XRD patterns of the investigated steel before and after tensile deformation at different temperatures. ((Before test, $\varepsilon=0),\left(25^{\circ} \mathrm{C}, \varepsilon=55 \%\right),\left(300{ }^{\circ} \mathrm{C}, \varepsilon=36 \%\right),\left(500{ }^{\circ} \mathrm{C}, \varepsilon=44 \%\right),\left(600{ }^{\circ} \mathrm{C}\right.$, $\varepsilon=64 \%)$ ).

Table 2. Volume fraction of constituent phases estimated by X-ray diffraction (vol\%).

\begin{tabular}{ccccc}
\hline Sample & $\gamma$ & $\alpha_{\mathbf{F}}$ & $\varepsilon$ & $\alpha^{\prime}$ \\
\hline Undeformed sample & 66.4 & 25.8 & 7.8 & 0 \\
25-sample & 51.6 & 25.7 & 6.9 & 15.8 \\
300-sample & 73.3 & 26.7 & 0 & 0 \\
500-sample & 74.1 & 25.9 & 0 & 0 \\
600-sample & 73.2 & 26.8 & 0 & 0 \\
\hline
\end{tabular}

The OM and SEM micrograph of the experimental steel before deformation are presented in Figure 4. As shown in Figure 4, the annealing twins were present in majority of austenite grains of the sample before the tensile test, and most of the annealing twins were present across the entire austenite grains. After deformation at room temperature, thin lamellar deformation twins (or $\alpha^{\prime}$-martensite) nucleated in the austenite matrix and the austenite grains were divided and refined (see Figure 5a). It can be seen from Figure $5 b-d$ that the volume fraction of mechanical twins and $\alpha$-martensite were 
remarkably reduced when the deformation temperature was increased to $300-600{ }^{\circ} \mathrm{C}$. This means that the TRIP effect and TWIP effect were inhibited with the increase of temperature.
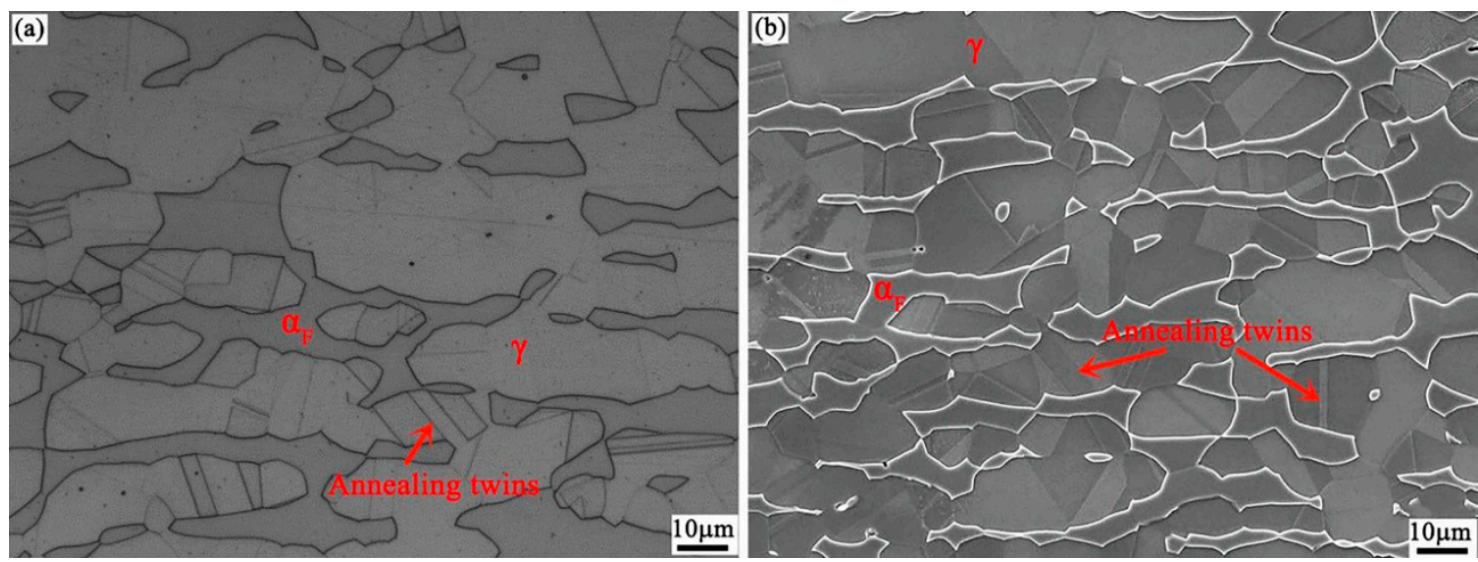

Figure 4. OM (a) and SEM (b) micrographs of the experimental steel before deformation at $25^{\circ} \mathrm{C}(\varepsilon=0)$.
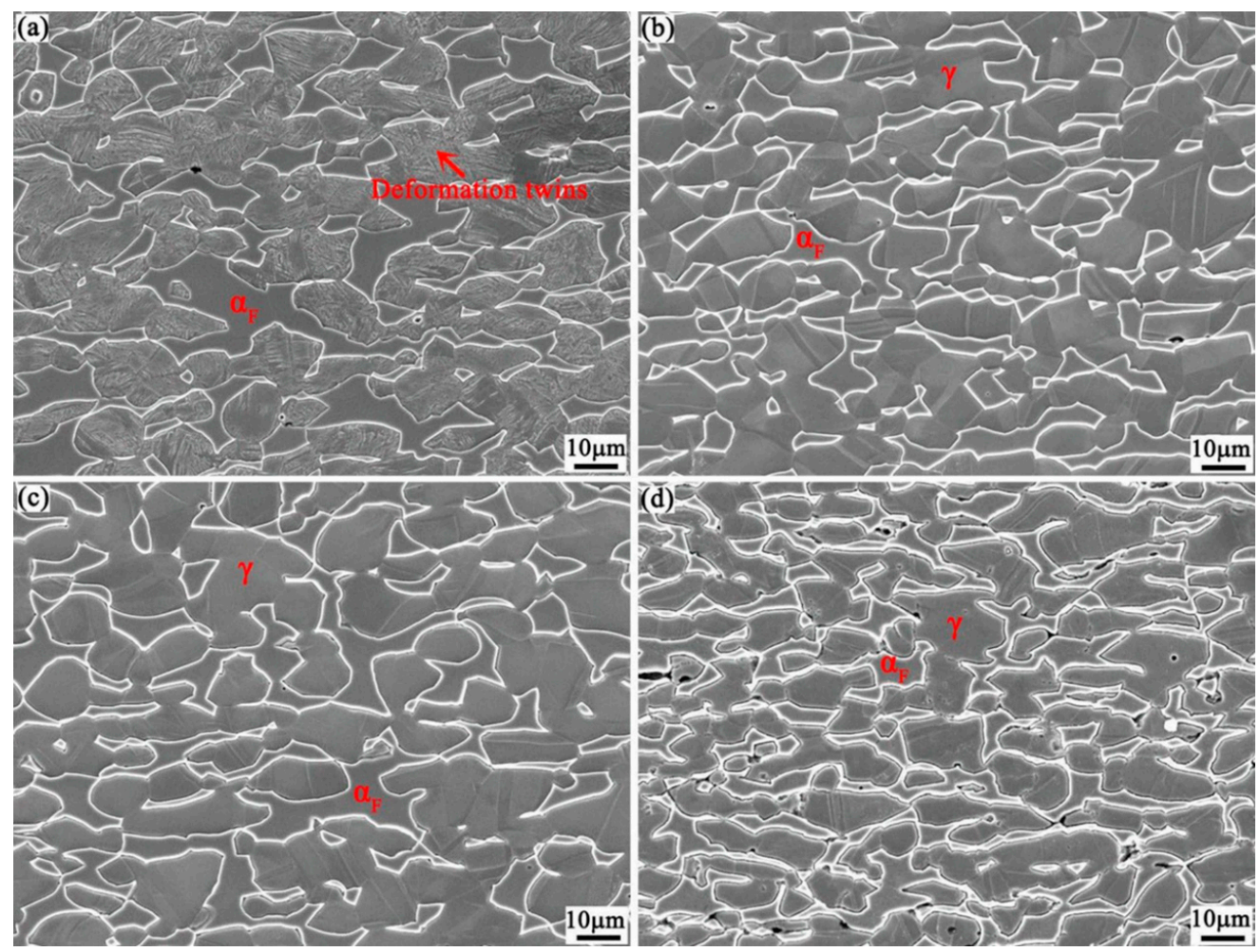

Figure 5. SEM micrographs of the experimental steel after deformation at different temperatures of (a) $25{ }^{\circ} \mathrm{C}, \varepsilon=55 \%$; (b) $300{ }^{\circ} \mathrm{C}, \varepsilon=36 \%$; (c) $500{ }^{\circ} \mathrm{C}, \varepsilon=44 \%$; and (d) $600{ }^{\circ} \mathrm{C}, \varepsilon=64 \%$.

TEM studies were conducted to reveal stacking faults, deformation twins, $\alpha$-martensite and the dislocation substructure development at different temperatures of deformation. Before deformation, the annealing twins (Figure 6a) and abundant stacking faults (Figure 6b) were present in the austenite matrix of experimental steel. The abundant stacking faults can provide favorable conditions for the subsequent strain-induced nucleation of martensite and deformation twins [4]. On deformation at room temperature $\left(25^{\circ} \mathrm{C}\right)$, deformation twins were observed in the austenite grain (Figure 7a). Meanwhile, $\alpha^{\prime}$-martensite (confirmed by electron diffraction pattern analysis) transformed from austenite during deformation (shown in Figure $7 \mathrm{~b}$ ), which indicated that the deformation-induced 
twins (TWIP effect) coexisted with deformation-induced $\alpha^{\prime}$-martensite (TRIP effect) and was the predominant deformation mechanism during tensile deformation at room temperature. When the tensile deformation temperature was increased to $300^{\circ} \mathrm{C}$, some dislocation activity was observed with a number of dislocations and dislocation walls (Figure $7 \mathrm{c}, \mathrm{d}$ ). This may be because the temperature of the steel was increased significantly, which led to the increase of SFE, and TRIP and TWIP effect were inhibited, but the dislocation slip was favored $[7,29]$. When the deformation temperature was $600{ }^{\circ} \mathrm{C}$, dislocation cells and slip bands were observed (Figure 7e,f). Thus, dislocation slip was the main deformation mechanism in the high deformation temperature region.
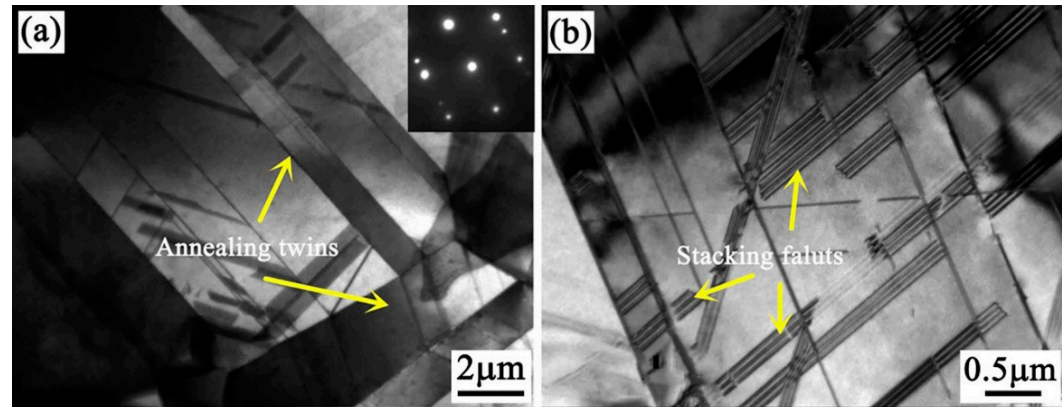

Figure 6. TEM micrographs of the experimental steel before deformation at $25^{\circ} \mathrm{C}(\varepsilon=0)$.
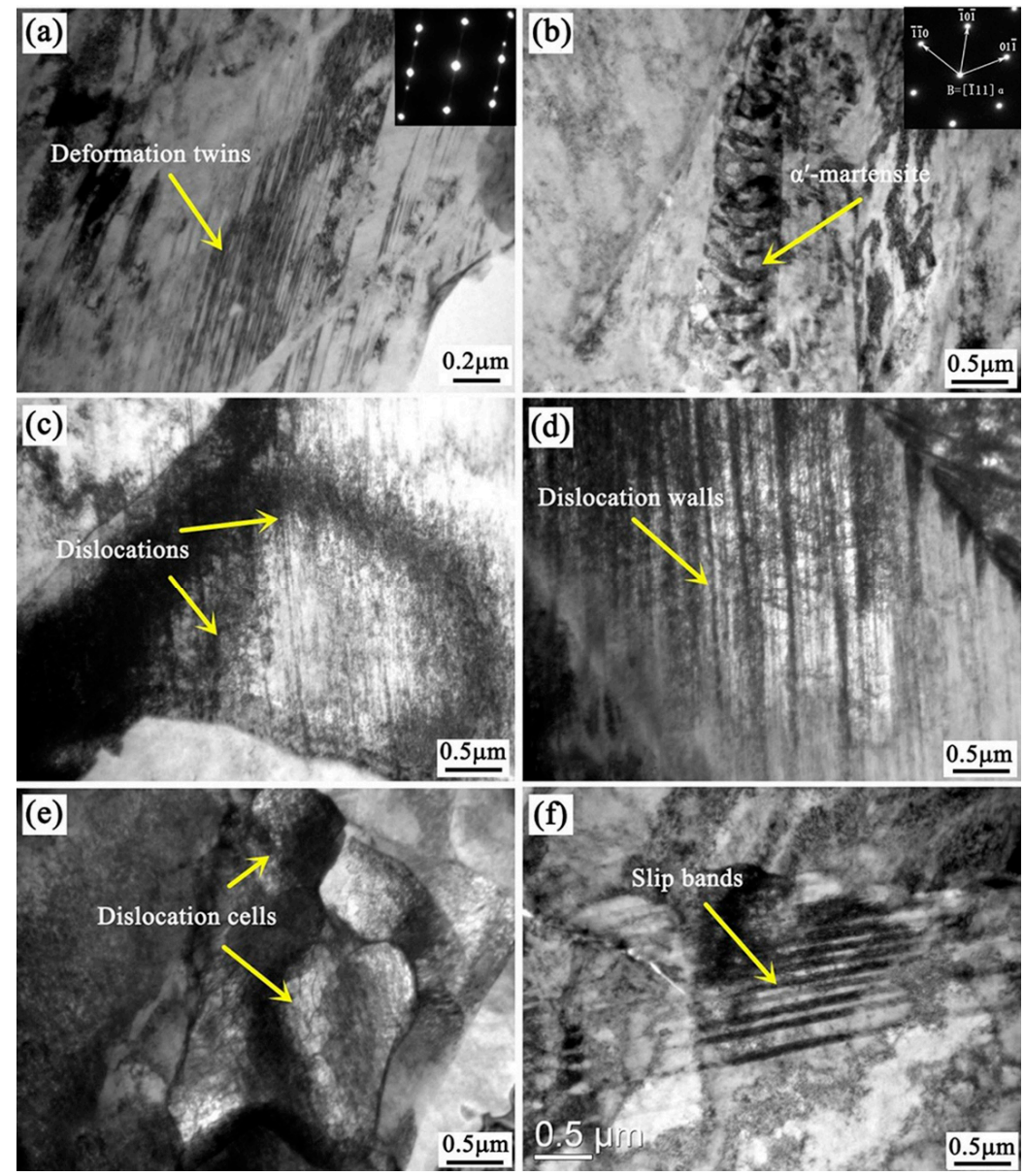

Figure 7. TEM micrographs of the experimental steel after deformation at different temperatures of $(\mathbf{a}, \mathbf{b}) 25{ }^{\circ} \mathrm{C}, \varepsilon=55 \%$; (c,d) $300{ }^{\circ} \mathrm{C}, \varepsilon=36 \%$; and $(\mathbf{e}, \mathbf{f}) 600{ }^{\circ} \mathrm{C}, \varepsilon=64 \%$. 


\section{Discussion}

\subsection{Effect of Deformation Temperature on the Deformation Mechanism}

It is known that the deformation temperature has a significant influence on microstructural development during deformation of experimental steel. The temperature change changes SFE, and the deformation behavior of high Mn steels is strongly related to SFE [9,30]. It is well known that the SFE increases with temperature $[7,20]$. For tests at different temperatures, the temperature rise $(\Delta T)$ is enough to affect the SFE. According to the thermodynamic models [31], the value of SFE can be calculated by the equation proposed by Saeed-Akbari et al. [20]. The change in SFE caused by $\Delta \mathrm{T}$ is shown in Figure 8. It can be seen that the SFE increased with the increase of deformation temperature. The SFE value of the investigated steel at room temperature was $14.5 \mathrm{mJm}^{-2}$. With the increase of temperature from 200 to $600{ }^{\circ} \mathrm{C}$, the SFE approached 40.0,54.7,69.4, 84.1, and $98.8 \mathrm{mJm}^{-2}$, respectively. According to Allain et al. [6] martensitic transformation occurs below $18 \mathrm{mJm}^{-2}$ and twinning between 12 and $35 \mathrm{mJm}^{-2}$ in the Fe-Mn-C TWIP steel. Curtze et al. [21] reported that twinning occurred at SFE: of $\sim 18 \mathrm{mJm}^{-2} \leq \mathrm{SFE} \leq 45 \mathrm{mJm}^{-2}$. When SFE $>45 \mathrm{mJm}^{-2}$, plasticity and strain hardening were controlled solely by the glide of dislocations. Thus, the strain induced martensitic transformation and deformation twinning coexisted at the room temperature deformation because the SFE $\left(14.5 \mathrm{mJm}^{-2}\right)$ is relatively low (see Figures $5 a$ and $7 a, b$ ). Then, the SFE increased with increase in temperature, TRIP effect and TWIP effect were suppressed (see Figure $5 b-d$ ). When the temperature was greater than $300{ }^{\circ} \mathrm{C}$, twinning was replaced by dislocation slip because the SFE was greater than $45 \mathrm{mJm}^{-2}$ (see Figure 7c-f).

In addition, the serrated flow (characteristic of DSA) occurred between 200 and $400{ }^{\circ} \mathrm{C}$ (see Figure 1) and implies that DSA effect has a significant effect on the mechanical properties of experimental steel in the temperature range of $200-400^{\circ} \mathrm{C}$, which is similar to the results of Bayramin et al. [16]. The SFE was in the range of 40.0 to $69.4 \mathrm{mJm}^{-2}$ with the increase of temperature from 200-400 ${ }^{\circ} \mathrm{C}$. Dislocation slip replaced TRIP/TWIP effect in this temperature range. The moving dislocations were pinned by solute atoms resulting in serrated flow at $200-400{ }^{\circ} \mathrm{C}$ [32]. If temperature is too high or too low, solute interstitial atoms (C-atom) may not be able to rearrange themselves with mobile dislocations and hinder them, therefore, the DSA did not take place $[15,33]$.

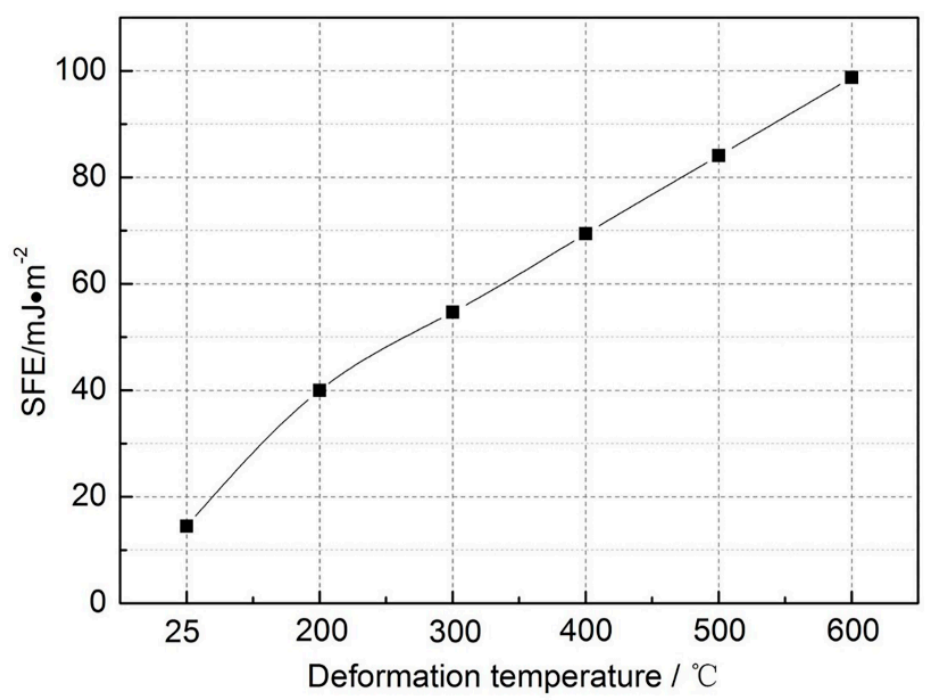

Figure 8. Estimation of SFE with the different deformation temperatures.

\subsection{Tensile Properties Difference at Different Temperatures}

It may be noted from Figure 1 and Table 1 that the experimental steel presents an exceptional mechanical properties with a PSE of $49.3 \mathrm{GPa}$ at room temperature, and the mechanical properties 
deteriorated with the increase of deformation temperature. The mechanical properties are directly related to the work hardening behavior depending on the mechanisms. 25-sample exhibited the highest UTS (905 MPa) and a good plasticity with the TEL of 55\%, and a rapid increase in the $n$ value in $S_{2}$ (see Figure 2a), because of strain induced martensitic transformation (TRIP effect) and strain induced deformation twinning (TWIP effect) (see Figure 3, Figure 5a, and Figure 7a,b). The formation of martensite and deformation twins act as planar obstacles to dislocation glide during deformation and enhanced the $\mathrm{n}$ values (high work hardening rate), delayed necking, which improves the plasticity of the experimental steel and results in highest UTS [2,3,18,34]. It should be also noted that the increase of $n$ value of 25-sample exceeded other samples (see Figure 2). It can be deduced that the TRIP effect and TWIP effect had the most beneficial effect on work hardening among all the deformation modes. With increase of deformation temperature to 200,300 , and $400{ }^{\circ} \mathrm{C}$, the UTS of 200-sample, 300-sample, and 400-sample decreased to 690,670 , and $650 \mathrm{MPa}$, respectively. Meanwhile, the TEL was only $\sim 36 \%$. As shown in Figure $2 b-d$, the $n$ value for the three samples exhibited an intense fluctuation in $S_{2}$ resulting from DSA. The decrease of UTS was due to thermal softening effect. TRIP effect and TWIP effect were suppressed and gradually replaced by dislocation slip with the increase in temperature. In this temperature range, high dislocation density and highly dense dislocation walls (see Figure 7c,d), were the main contributors in enhancing work hardening behavior. Their strengthening effect is weaker than TRIP effect and TWIP effect, hence, UTS was decreased. As regards, low plasticity (TEL of 36\%), it is because the TRIP effect and TWIP effect were suppressed. In addition, the role of DSA phenomenon should be taken into account. The DSA took place in this temperature range, and an inhomogeneous plastic deformation because of successive locking of the mobile dislocations and strain localization took place, which prevented high TEL to be obtained [15]. When the deformation temperature was increased to $500-600{ }^{\circ} \mathrm{C}$, high-temperature softening occurred and the UTS of samples was further decreased with the increase of elongation.

\section{Conclusions}

In the present study, the microstructure and mechanical properties of cold-rolled Fe-18Mn-3Al-3Si-0.03C TRIP/TWIP steel in the temperatures range of 25 to $600{ }^{\circ} \mathrm{C}$ was studied. The main conclusions are as follows:

1. Fe-18.1Mn-3.1Al-3.2Si-0.03C TRIP/TWIP steel exhibited excellent mechanical properties at room temperature. The UTS, TEL and PSE were $905 \mathrm{MPa}, 55 \%$ and $49.3 \mathrm{GPa}$, respectively. The dominant plasticity mechanism at room temperature was strain induced martensite deformation and deformation twinning.

2. With the increase of deformation temperature from 25 (room temperature) to $600{ }^{\circ} \mathrm{C}$, the SFE of the experimental steel was in the range of 14.5 to $98.8 \mathrm{mJm}^{-2}$. The deformation mechanism of the experimental steel is controlled by both the strain induced martensite formation and strain induced deformation twinning at $25^{\circ} \mathrm{C}$. With the increase of deformation temperature from 25 to $600^{\circ} \mathrm{C}$, TRIP and TWIP effects were inhibited, and dislocation glide gradually became the main deformation mechanism.

3. The UTS decreased monotonously from 905 to $325 \mathrm{MPa}$ and the TEL decreased (from 55 to $36 \%$, $25-400{ }^{\circ} \mathrm{C}$ ) and then increased (from 36 to $64 \%, 400-600{ }^{\circ} \mathrm{C}$ ). The change in mechanical properties was related to the thermal softening effect, TRIP effect, TWIP effect, DSA, and dislocation slip.

Author Contributions: Z.T. and J.H. designed most of the experiments, performed most experiments, analyzed the results, and wrote this manuscript. Z.C., H.D., D.Z., and D.M. helped analyze the experiment data and gave some constructive suggestions about how to write this manuscript.

Funding: This research received no external funding.

Acknowledgments: The research was supported by the National Natural Science Foundation of China (grant Nos. 51574077 and 51501035) and the Fundamental Research Funds for the Central Universities (N120502005 and N170204017). R.D.K. Misra acknowledges continued collaboration with Northeastern University as an Honorary Professor in providing guidance to students in research. 
Conflicts of Interest: The authors declare no conflict of interest.

\section{References}

1. Ding, H.; Tang, Z.Y.; Li, W.; Wang, M.; Song, D. Microstructures and mechanical properties of Fe-Mn-(Al, Si) TRIP/TWIP steels. J. Iron Steel Res. 2006, 13, 66-70. [CrossRef]

2. Ding, H.; Ding, H.; Song, D.; Tang, Z.Y.; Yang, P. Strain hardening behavior of a TRIP/TWIP steel with $18.8 \%$ Mn. Mater. Sci. Eng. A 2011, 528, 868-873. [CrossRef]

3. Shterner, V.; Timokhina, I.B.; Beladi, H. On the work-hardening behaviour of a high manganese TWIP steel at different deformation temperatures. Mater. Sci. Eng. A 2016, 669, 437-446. [CrossRef]

4. Tang, Z.Y.; Misra, R.D.K.; Ma, M.; Zan, N.; Wu, Z.Q.; Ding, H. Deformation twinning and martensitic transformation and dynamic mechanical properties in Fe-0.07C-23Mn-3.1Si-2.8Al TRIP/TWIP steel. Mater. Sci. Eng. A 2015, 624, 186-192. [CrossRef]

5. Dufay, A.; Chateau, J.P.; Allain, S.; Migot, S.; Bouaziz, O. Influence of addition elements on the stacking-fault energy and mechanical properties of an austenitic Fe-Mn-C steel. Mater. Sci. Eng. A 2008, 483-484, $184-187$.

6. Allain, S.; Chaterau, J.P.; Bouaziz, O.; Migot, S.; Guelton, N. Correlations between the calculated stacking fault energy and the plasticity mechanisms in Fe-Mn-C alloys. Mater. Sci. Eng. A 2004, 387-389, $158-162$. [CrossRef]

7. Linderov, M.; Segel, C.; Weidner, A.; Biermann, H.; Vinogradov, A. Deformation mechanisms in austenitic TRIP/TWIP steels at room and elevated temperature investigated by acoustic emission and scanning electron microscopy. Mater. Sci. Eng. A 2014, 597, 183-193. [CrossRef]

8. Pierce, D.T.; Jiménez, J.A.; Bentley, J.; Raabe, D.; Witting, J.E. The influence of stacking fault energy on the microstructural and strain-hardening evolution of Fe-Mn-Al-Si steels during tensile deformation. Acta Mater. 2015, 100, 178-190. [CrossRef]

9. Kim, J.K.; Chen, L.; Kim, H.S.; Kim, S.K.; Estrin, Y.; De Cooman, B.C. On the tensile behavior of high-manganese twinning-induced plasticity steel. Metall. Mater. Trans. A 2009, 40, 3147-3158. [CrossRef]

10. Chen, L.; Kim, H.S.; Kim, S.K.; De Cooman, B.C. Localized deformation due to Portevin-LeChatelier effect in 18Mn-0.6C TWIP austenitic steel. ISIJ Int. 2007, 47, 1804-1812. [CrossRef]

11. Lee, S.J.; Kim, J.Y.; Kane, S.N.; De Cooman, B.C. On the origin of dynamic strain aging in twinning-induced plasticity steels. Acta Mater. 2011, 59, 6809-6819. [CrossRef]

12. Kim, J.G.; Hong, S.; Anjabin, N.; Park, B.H.; Kim, S.K.; Chin, K.G.; Lee, S.; Kim, H.S. Dynamic strain aging of twinning-induced plasticity (TWIP) steel in tensile testing and deep drawing. Mater. Sci. Eng. A 2015, 633, 136-143. [CrossRef]

13. Taheri, A.K.; Maccagno, T.M.; Jonas, J.J. Dynamic strain aging and the wire drawing of low carbon steel rods. ISIJ Int. 1995, 35, 1532-1540. [CrossRef]

14. Li, C.C.; Leslie, W.C. Effects of dynamic strain aging on the subsequent mechanical properties of carbon steels. Metall. Trans. A 1978, 9, 1765-1775. [CrossRef]

15. Shahriary, M.S.; Koohbor, B.; Ahadi, K.; Ekrami, A.; Khakian-Qomi, M.; Izadyar, T. The effect of dynamic strain aging on room temperature mechanical properties of high martensite dual phase (HMDP) steel. Mater. Sci. Eng. A 2012, 550, 325-332. [CrossRef]

16. Bayramin, B.; Şimşir, C.; Efe, M. Dynamic strain aging in DP steels at forming relevant strain rates and temperatures. Mater. Sci. Eng. A 2017, 704, 164-172. [CrossRef]

17. Jung, I.C.; De Cooman, B.C. Temperature dependence of the flow stress of Fe-18Mn-0.6C-xAl twinning-induced plasticity steel. Acta Mater. 2013, 61, 6724-6735. [CrossRef]

18. Benzing, J.T.; Poling, W.A.; Pierce, D.T.; Witting, J.E. Effects of strain rate on mechanical properties and deformation behavior of an austenitic Fe-25Mn-3Al-3Si TWIP-TRIP steel. Mater. Sci. Eng. A 2018, 711, 78-92. [CrossRef]

19. Asghari, A.; Zarei-Hanzaki, A.; Eskandari, M. Temperature dependence of plastic deformation mechanisms in a modified transformation-twinning induced plasticity steel. Mater. Sci. Eng. A 2013, 579, 150-156. [CrossRef]

20. Saeed-Akbari, A.; Imlau, J.; Prahl, U.; Bleck, W. Derivation and variation in composition-dependent stacking fault energy maps based on subregular solution model in high-manganese steels. Metall. Mater. Trans. A 2009, 40, 3076-3090. [CrossRef] 
21. Curtze, S.; Kuokkala, V.T. Dependence of tensile deformation behavior of TWIP steels on stacking fault energy, temperature and strain rate. Acta Mater. 2015, 58, 5129-5141. [CrossRef]

22. Allain, S.; Chateau, J.P.; Bouaziz, O. A physical model of the twinning-induced plasticity effect in a high manganese austenitic steel. Mater. Sci. Eng. A 2004, 387-389, 143-147. [CrossRef]

23. Renard, K.; Ryelandt, S.; Jacques, P.J. Characterisation of the Portevin-Le Châtelier effect affecting an austenitic TWIP steel based on digital image correlation. Mater. Sci. Eng. A 2010, 527, 2969-2977. [CrossRef]

24. Martin, S.; Wolf, S.; Martin, U.; Krüger, L.; Rafaja, D. Deformation mechanisms in austenitic TRIP/TWIP steel as a function of temperature. Metall. Mater. Trans. A 2016, 47, 49-58. [CrossRef]

25. Eskandari, M.; Zarei-Hanzaki, A.; Marandi, A. An investigation into the mechanical behavior of a new transformation-twinning induced plasticity steel. Mater. Des. 2012, 39, 279-284. [CrossRef]

26. Lan, P.; Zhang, J.Q. Twinning and dynamic strain aging behavior during tensile deformation of Fe-Mn-C TWIP steel. Mater. Sci. Eng. A 2017, 700, 250-258. [CrossRef]

27. Jacques, P.; Ladriere, J.; Delannay, F. On the influence of interactions between phases on the mechanical stability of retained austenite in transformation-induced plasticity multiphase steels. Metall. Mater. Trans. A 2001, 32, 2759-2768. [CrossRef]

28. Egea, A.J.S.; Rojas, H.A.G.; Celentano, D.J.; Peiró, J.J. Mechanical and metallurgical changes on 308L wires drawn by electropulses. Mater. Des. 2016, 90, 1159-1169. [CrossRef]

29. Lee, S.; Estrin, Y.; De Cooman, B.C. Effect of the strain rate on the TRIP-TWIP transition in austenitic Fe-12 pct Mn-0.6 pct C TWIP steel. Metall. Mater. Trans. A 2014, 45, 717-730. [CrossRef]

30. Van der Wegen, G.J.L.; Bronsveld, P.M.; Hosson, J.T.M. A comparison between different theories predicting the stacking fault energy from extended nodes. Scr. Metall. 1980, 4, 285-288. [CrossRef]

31. Ferreira, P.J.; Müllner, P. A thermodynamic model for the stacking-fault energy. Acta Mater. 1998, 46, 4479-4484. [CrossRef]

32. Peng, K.P.; Qian, K.W.; Chen, W.Z. Effect of dynamic strain aging on high temperature properties of austenitic stainless steel. Mater. Sci. Eng. A 2004, 379, 372-377. [CrossRef]

33. Molaei, M.J.; Ekrami, A. The effect of dynamic strain aging on fatigue properties of dual phase steels with different martensite morphology. Mater. Sci. Eng. A 2009, 527, 235-238. [CrossRef]

34. Bouaziz, O.; Allain, S.; Scott, C. Effect of grain and twin boundaries on the hardening mechanisms of twinning-induced plasticity steels. Scr. Mater. 2008, 58, 484-487. [CrossRef] 